\title{
METABOLISMO DE CARBOIDRATOS NÃO-ESTRUTURAIS EM RUMINANTES
}

\section{Metabolism of non-structural carbohydrates in ruminants}

\author{
CAÑIZARES, G.I.L. ${ }^{1}$; RODRIGUES, L. ${ }^{1}$; CAÑIZARES, M.C. ${ }^{1}$ \\ ${ }^{1}$ Aluno de Doutorado - Programa de Pós-Graduação em Zootecnia - FMVZ/Unesp-Campus Botucatu/SP.
}

Os carboidratos constituem de 50 a $80 \%$ da matéria seca dos volumosos e grãos e podem ser divididos em estruturais (celulose, hemicelulose) e não-estruturais (amido, pectina e açúcares). Os carboidratos não-estruturais são digeridos principalmente no rúmen e seu processo é uma seqüência dinâmica para o fornecimento de nutrientes ao intestino. A qualidade e a quantidade de produtos resultantes da fermentação ruminal são dependentes do tipo e atividade dos microrganismos do rúmen influenciado pelo tipo de alimentação e processamento em que são submetidos os grãos de cereais que compõe a dieta. Os CNE escapam da fermentação ruminal para serem digeridos em glicose no intestino delgado pelas enzimas de origem pancreáticas ( $\alpha$-amilase) e mucosa intestinal (maltase e isomaltase). $\mathrm{O}$ amido é o maior componente fornecedor de energia dos grãos de cereais, os quais são importantes componentes das dietas utilizadas para as produções intensivas de leite e carne.

Palavras-chave: amido, digestão de carboidratos, fermentação ruminal, glicose, pectina

\section{ABSTRACT}

The carbohydrates provide 50 to $80 \%$ of the dry matter of grain and roughage and can be divided into structural (cellulose, hemicellulose) and non-structural (starch, pectin and sugars). The non-structural carbohydrates are primarily digested in the rumen and its dynamic process is a sequence for the supply of nutrients to the intestine. The quality and quantity of products resulting from ruminal fermentation are dependent on the type and activity of microorganisms in the rumen influenced by the type of food processing and that are subject of cereal grains that make up the diet. The NSC escape of rumen fermentation to be digested into glucose in the small intestine by pancreatic enzymes of origin ( $\alpha$ amylase) and intestinal mucosa (maltase and isomaltase). Starch is the most important energy supplier of cereals, which are important components of diets for intensive production of milk and meat.

Key words: carbohydrates digestion, glucose, pectin, ruminal fermentation, starch 


\section{INTRODUÇÃO}

$\mathrm{Na}$ nutrição de ruminantes o alimento consumido é retido no rúmen para sua fermentação. Nesse local, forças físicas, químicas e biológicas interagem para seu desdobramento e retenção. As partículas alimentares que compõem as dietas são solubilizadas e misturadas com a fase líquida, sendo rapidamente fermentadas pelos microrganismos do rúmen e os compostos derivados do seu metabolismo irão nutrir o animal (Rodrigues e Vieira, 2006). A inclusão de carboidratos nãoestruturais como fonte de energia na alimentação de ruminantes tem sido observada como forma de aumentar a produtividade dos animais.

Os carboidratos não-estruturais são fermentados por bactérias ruminais como: Streptococcus bovis, Ruminobacter amylophilus, Lactobacillus $s p$ etc., em produtos finais que são os ácidos graxos voláteis (AGV) que irão servir como fonte de energia para seu crescimento e produção de proteína microbiana.

Esta revisão tem como objetivo explorar as informações existentes sobre carboidratos não-estruturais e sua importância na nutrição de ruminantes.

\section{DESENVOLVIMENTO}

\section{CARBOIDRATOS}

Os carboidratos constituem de 50 a $80 \%$ da matéria seca dos volumosos e grãos. Seu valor nutritivo depende de sua composição em açúcares e de suas ligações com compostos fenólicos. A disponibilidade nutricional dos carboidratos depende da capacidade dos animais em quebrar as ligações glicosídicas nos diferentes carboidratos e outras substâncias (Van Soest, 1994).

Desde o século XIX, carboidratos que não sejam fibra bruta ou fibra solúvel em detergente neutro têm sido calculados ou estimados por diferença. Estes carboidratos foram chamados de extrativos não nitrogenados, e mais recentemente de carboidratos não fibrosos (CNF). Os CNF continuam a ser calculados, preferencialmente, ao invés de analisados diretamente, devido aos vários tipos de carboidratos incluídos nesta fração (Teixeira e Andrade, 2001).

Em relação à disposição histológica na planta, os carboidratos podem ser divididos em estruturais (celulose, hemicelulose) e não-estruturais (amido, pectina e açúcares).

O grupo dos carboidratos não estruturais é constituído pelos açúcares e amido, sendo assim classificados por estarem presentes no conteúdo celular e serem fontes de energia prontamente disponíveis ou de reserva para a planta (De Visser, 1993; Chesson e Monro, 1982). A exceção é a pectina, que é um polissacarídeo amorfo contido na parede celular, mas classificado como carboidrato não estrutural por ser totalmente solúvel em detergente neutro e ser rápida e extensamente degradável pelos microrganismos ruminais (Van Soest, 1994).

Os CNE também podem ser classificados como solúveis em água (incluindo monossacarídeos, dissacarídeos, oligossacarídeos e alguns polissacarídeos) e polissacarídeos maiores que são insolúveis em água. Carboidratos nãoestruturais solúveis em água, como açúcares (glicose e frutose) e dissacarídeos (sacarose e lactose) são rapidamente fermentados no rúmen e incluem uma fração significante em alguns alimentos utilizados na dieta dos ruminantes (melaço, polpa da beterraba etc.).

As pectinas são carboidratos associados com a parede celular, mas não são covalentemente unidos às porções lignificadas e são digeridas completamente no rúmen (90 a 100\%). Hatfield e Weimer (1995) encontraram que a quantidade de pectina variou entre as diferentes partes da planta, possuindo as folhas e hastes da 
alfafa, em média, $25 \%$ a $30 \%$ e $10 \%$ a $20 \%$ da parede celular com pectina, respectivamente. Alguns subprodutos da agro-indústria são particularmente ricos em pectina,como a polpa de beterraba e de outros tubérculos ( $25 \%$ de pectina), polpa cítrica $(25 \%)$ e polpa de maçã seca $(19 \%)$. Desses, a polpa cítrica é a fonte mais comum de pectina na dieta dos ruminantes (Ben-Ghedalia et al., 1989; Henrique et al., 1998).

Segundo Hall (2001), um ponto fraco do cálculo de carboidratos não fibrosos é que essa fração coloca todos os carboidratos solúveis em detergente neutro (CSDN) em um único "pool". Este grupo, nutricionalmente diverso, inclui tanto carboidratos estruturais (parede celular), como carboidratos não-estruturais (conteúdos celulares) e carboidratos fibrosos e não fibrosos.

Os ácidos orgânicos não são carboidratos, mas são, frequentemente, agrupados com CSDN a fim de descrever os componentes do alimento. Diferentes CSDN tendem a predominar em diferentes alimentos.

CARBOIDRATOS NÃO-ESTRUTURAIS NA ALIMENTAÇÃO DE RUMINANTES

Os carboidratos não-estruturais dos alimentos para ruminantes são compostos por moléculas de monossacarídeos (cinco carbonos: ribose, arabinose, xilose $e$ pectina e seis carbonos: glicose, galactose e frutose).

Uma pequena parte dos CNE das plantas são monômeros livres que pela sua solubilidade são rapidamente usados por estas, como intermediários de compostos complexos ou como carregadores de energia. Estes monômeros combinam-se para formarem polissacarídeos, onde 0 dissacarídeo mais frequente nas plantas é a sacarose (glicose + frutose) que é armazenada no caule ou precursora para síntese de polissacarídeo de reserva (amido) (Antunes e Rodrigues, 2006).
A produção de ruminantes no Brasil está fundamentada, principalmente na utilização das pastagens; sendo assim, a forragem deve suprir todos os nutrientes exigidos pelos animais. Entretanto, devido a disponibilidade limitada e a baixa quantidade de forragens em virtude dos fatores climáticos, torna-se necessária a suplementação energética dos animais. A suplementação contendo altas quantidades de carboidratos não-estruturais, como grãos de cereais, tem diminuído a ingestão e digestibilidade de forragens de baixa qualidade (Olson et al., 1999; Bodine et al., 2001). Os mecanismos pelos quais altas quantidades de CNE podem deprimir a ingestão e digestibilidade da forragem incluem diminuição no pH ruminal, diminuição na produção e atividade de enzimas celulolíticas (Martin et al., 1999), prejudicando o ataque bacteriano à fibra da digesta (Hiltner e Dehority, 1983), e aumentando o "lag time" para a digestão da fibra (Mertens e Loften, 1980).

Quantidades limitadas de CNE estimulam a digestão da fibra, possivelmente pelo aumento na atividade microbiana e sua fixação à fibra da digesta (Hiltner e Dehority, 1983; Piwonka e Firkins, 1996). Subprodutos com alta fibra contendo baixas quantidades de CNE, como casca de soja, tem aumentado a utilização de forragens de baixa qualidade pelos bovinos, possivelmente porque a degradação de amido por microrganismos e as flutuações no $\mathrm{pH}$ sejam menores (Hsu et al., 1987).

DIGESTÃO RUMINAL DOS CARBOIDRATOS NÃO-ESTRUTURAIS

Os carboidratos não-estruturais são digeridos principalmente no rúmen pelos microrganismos e seu processo é uma seqüência dinâmica para o fornecimento de nutrientes ao intestino. A energia fornecida desempenha papel importante para síntese de proteína microbiana, já que esta pode ser limitada pela baixa disponibilidade de 
carboidratos não-estruturais, os quais são fontes de ATP.

Grande parte do processo de fermentação dos CNE no rúmen é realizado pelas bactérias ficando uma pequena parte para protozoários e fungos, onde o produto da fermentação são os ácidos graxos voláteis (AGV), $\mathrm{CO}_{2}, \mathrm{H}_{2}$, metano e lactato.

As bactérias são responsáveis pela maior parte da digestão dos alimentos no rúmen, por causa da sua predominância numérica e pela diversidade metabólica. Os protozoários são os microrganismos ruminais de maior tamanho e podem contribuir com $40 \%$ a $50 \%$ da biomassa e da atividade enzimática total no rúmen (Jouany, 1991; Williams e Coleman, 1997). Os fungos ruminais atuam sobretudo na digestão da fibra, pois a biomassa de fungos aumenta substancialmente em dietas ricas em volumosos e praticamente está ausente em dietas ricas em concentrados à base de grãos de cereais (Fonty, 1991; Orpin e Joblin, 1997).

A qualidade e a quantidade de produtos resultantes da fermentação ruminal são dependentes do tipo e atividade dos microrganismos do rúmen, influenciado pelo tipo de alimentação. O ecossistema microbiano ruminal é muito diverso. Além disso, existem diversas inter-relações entre esses microrganismos.

O Sistema CNCPS (Sistema de Carboidratos e Proteínas Líquidas de Cornell) divide o ecossistema dos microrganismos ruminais em dois grupos: microrganismos que fermentam carboidratos não-estruturais (CNE) e aqueles que fermentam carboidratos estruturais (CE). Esta separação reflete a diferença na utilização de $\mathrm{N}$ e eficiência no crescimento, assim como uma separação na utilização da fonte de energia. As bactérias fermentadoras dos CE: Ruminococcus albus, Ruminococcus flavefaciens, Fibrobacter succinogenes; fermentam apenas carboidratos da parede celular, utilizam apenas amônia como fonte de $\mathrm{N}$ e não fermentam peptídeos ou aminoácidos. As bactérias fermentadoras dos CNE: Streptococcus bovis, Ruminobacter amylophilus, Lactobacillus $s p$; fermentam carboidratos não-estruturais (amido, pectina, açúcares), utilizam tanto amônia como peptídeos e aminoácidos como fonte de $\mathrm{N}$ e podem produzir amônia. Algumas bactérias do gênero Butyrivibrio fibrisolvens podem fermentar amido e celulose e produzir amônia, mas degradam celulose em uma taxa muito lenta em relação às outras bactérias celulolíticas. No sistema CNCPS, B. fibrisolvens pode ser classificada como fermentadora de CNE (Russell et al., 1992).

Segundo Palmquist e Jenkins (1980), a suplementação com gordura para aumentar a densidade energética das dietas para ruminantes tem sido utilizada com bastante frequência.

Entretanto, essa suplementação pode afetar negativamente a digestão ruminal de carboidratos por meio de efeito inibitório dos ácidos graxos de cadeia longa na digestão da fibra. Dessa maneira, Zinn e Owens (1986), observaram que a suplementação com gordura foi associada à diminuição da fermentação ruminal de carboidratos, redução na digestão ruminal da fibra e mudança no local de digestão do rúmen para o intestino delgado. Por outro lado, Hussein et al. (1995) avaliando a suplementação com semente de canola sobre o local e extensão da digestão de carboidratos em novilhos, observaram que a ingestão e digestão de CNE não foi afetada pela suplementação.

Subprodutos que contêm alta quantidade de fibra altamente fermentescível no rúmen, como casca de soja, podem ser adicionados às dietas para minimizar os efeitos negativos associados à alta quantidade de CNE da dieta. Um balanço adequado de CNE e fibra em detergente neutro (FDN) na dieta pode otimizar a fermentação ruminal e maximizar a produção de leite, gordura e proteína. Segundo Nocek e Russell (1988), esta 
relação deve estar entre 0,9 e 1,2 para maximizar a produção. Essa relação equivale a 36 a $48 \%$ de FDN, que é considerado maior que 25 a $28 \%$, recomendado pelo NRC (1989).

Os CNE são rapidamente fermentados no rúmen, ocasionando redução do $\mathrm{pH}$ ruminal, diminuindo a atividade celulolítica e podendo deprimir a relação acetato:propionato. Entretanto uma quantidade suficiente de fibra na dieta é necessária para evitar a diminuição da gordura no leite (NRC, 1989). Feng et al. (1993) observaram que em dietas que proporcionavam baixas concentrações de FDN a partir de forragens, ou seja, de 29 a $39 \%$ de CNE, houve um aumento na produção de leite, produção microbiana e taxa de passagem ruminal. Em situações práticas, os CNE da dieta são ajustados pela mudança na relação concentrado: volumoso. Alguns estudos observaram os efeitos de alterar a concentração de CNE na produção de leite. Sarwar et al. (1992) observaram que diminuindo os CNE de 35 para $25 \%$ pela substituição de soja e casca de soja por milho grão, houve aumento na produção de leite. Entretanto, Coomer et al. (1993) não observaram efeito na produção e composição do leite em dietas que variaram de 28 a $38 \%$ o teor de CNE nas dietas.

\section{DIGESTÃO INTESTINAL DOS} CARBOIDRATOS NÃO-ESTRUTURAIS

Os carboidratos solúveis na sua quase totalidade são fermentados no rúmen, porém uma pequena parte destes, dependendo do processamento em que são submetidos os grãos de cereais que compõe a dieta, escapam da fermentação ruminal para serem digeridos no intestino delgado pelas enzimas de origem pancreáticas ( $\alpha$-amilase $)$ e mucosa intestinal (maltase e isomaltase).

A glicose que é absorvida pelo intestino não altera o teor de glicose no plasma, que se mantém em níveis baixos nos ruminantes. Isto indica que há grande exigência metabólica de glicose e esta é usada no metabolismo energético visceral.

$O$ efeito da relação concentrado: volumoso sobre o coeficiente de digestibilidade da matéria seca (MS) foi observado por Valadares Filho (1985), que notou maior coeficiente para o nível de $60 \%$ de concentrado. Segundo esse autor, isso ocorreu devido a maior concentração de carboidratos não-estruturais, uma vez que os CNE apresentaram digestibilidade aparente acima de $90 \%$ e os carboidratos estruturais, próximos de 50\%. Entretanto, Archimède et al. (1995), avaliando a digestão de ruminantes, observaram que não houve influência da suplementação com concentrado na digestibilidade dos CE, em exceção da dieta composta por silagem de milho e amido lentamente degradável.

Hussein et al. (1995) avaliando o nível de forragem no local e extensão da digestão de carboidratos por novilhos, observaram que animais alimentados com dieta contendo baixo nível de forragem (BF) apresentaram maior ingestão, maior digestão no estômago e pós-rúmen de CNE em relação aos animais da dieta com alto nível de forragem (AF). Esse resultado é consistente com o efeito do nível de forragem no local da digestão dos CNE. Quando a ingestão de CNE foi maior (nas dietas BF), menor proporção de CNE foi digerida no estômago, e consequentemente uma maior proporção foi digerida pós-rúmen.

Avaliando o efeito de carboidratos nãoestruturais na alimentação de vacas leiteiras, Feng et al. (1993) observaram maiores produções de leite para animais consumindo dietas com $29 \%$ de CNE em relação às dietas com $39 \%$ de $\mathrm{CNE}$, possivelmente pela maior quantidade de $\mathrm{N}$ total e $\mathrm{N}$ microbiano que passaram pelo duodeno. Esses autores também observaram maior porcentagem de gordura no leite para as vacas alimentadas com dietas contendo $29 \%$ de CNE (3,7 vs. 
$3,3 \%$ em relação às dietas com $39 \%$ de CNE.

\section{AMIDO}

O amido é o maior componente fornecedor de energia e representa 60 a $80 \%$ dos grãos de cereais, os quais são importantes componentes das dietas utilizadas para as produções intensivas de leite e carne. Por esta razão, a eficiência da digestão do amido por ruminantes é de grande importância econômica. Entretanto, uma predição exata da utilização dos grãos em uma dieta requer a estimativa da quantidade de amido e sua fermentação. $O$ trigo apresenta a maior quantidade de amido (77\%) seguido pelo sorgo (72\%), cevada e aveia (57 a 58\%), segundo Huntington (1997).

Huntington et al. (2006) reuniram dados de 16 estudos que incluíam ingestão (1 a 5 $\mathrm{kg} / \mathrm{dia}$ ) e fontes de amido (milho, sorgo e cevada), e estimaram relação linear entre ingestão e digestão ruminal aparente de amido. Esses autores concluíram que dentro das limitações das funções normais do rúmen, a quantidade de amido digerida é função linear da ingestão. Entretanto, outros fatores além da ingestão afetam a digestão de amido, como a cinética ruminal, partículas de alimentos e líquido e suas propriedades químicas $(\mathrm{pH}$, osmolaridade), taxa e extensão da passagem de partículas e produtos resultantes da síntese microbiana.

O processamento de grãos (umidade, calor e pressão mecânica) rompe a estrutura dos grânulos de amido e tem sido utilizado com sucesso para melhorar a fermentação ruminal dos grãos e sua digestibilidade pós-ruminal. Xiong et al. (1991) observaram que o processamento do sorgo por floculação aumentou a digestão de amido no rúmen, sendo menor a quantidade de amido disponível para a fermentação no intestino grosso.

Em geral, o aumento na quantidade de amido fermentescível proveniente de grãos na dieta é associado com aumento na produção de ácidos orgânicos, aumento na produção de proteína microbiana, diminuição na digestão da fibra, diminuição nas concentrações de amônia e diminuição na relação acetato:propionato (Martin et al., 1999; Oba e Allen, 2003).

A digestão ruminal do amido produz ácidos graxos voláteis para absorção e energia para a síntese microbiana. Diversas espécies de bactérias ruminais apresentam habilidade para digerir 0 amido. Organismos amilolíticos são encontrados em grandes porcentagens da população microbiana total quando dietas com alto amido são fornecidas. Espécies importantes vêm sido enumeradas em bovinos alimentados com dietas de alto grão, como Bacteroides amylophilus, Butyrivibrio fibrisolvens, Bacteroides ruminocola, Selenomona lactylitica, Streptococcus bovis, Prevotella ruminocola, Eubacterium ruminantium, Ruminobacter amylophilus, Ruminococcus bromii e Lactobacillus sp (Church, 1979).

A digestão e absorção de amido no intestino delgado de ruminantes ocorre em três processos distintos. O processo iniciase no lúmen do duodeno por meio da ação da a-amilase pancreática. Essa enzima inicia a quebra do amido produzindo maltose e vários produtos com cadeias ramificadas denominados comumente como dextrinas. A necessidade de uma resposta adaptativa do pâncreas dos ruminantes ao aumento do amido da dieta permanece um enigma biológico e está baseado na hipótese de que a a-amilase pancreática é a fase limitante da assimilação intestinal do amido (Kreikemeier et al., 1991).

A segunda fase da digestão e absorção intestinal do amido ocorre na membrana celular da mucosa intestinal por meio da ação das enzimas maltase e isomaltase. Kreikemeier e Harmon (1995) analisaram a composição da digesta ileal em novilhos com infusão abomasal de glicose, dextrose e amido do milho. Os autores observaram acúmulo de a-glucosídios na digesta ileal 
que era composta na sua maioria de dissacarídeos com pouca glicose livre, e concluíram que sob essas condições experimentais a assimilação do amido foi limitada pela atividade da $\alpha$-glicosidase.

$O$ terceiro e final componente da digestão e absorção intestinal do amido é o transporte da glicose para fora do lúmen intestinal e para a circulação do sistema porta. Entretanto, afirma-se que a glicose atravessa a membrana dos enterócitos por meio da ação do transportador glicose sódio-dependente (SGLT1) e a atividade desse transportador não tem mostrado resposta adaptativa ao substrato do lúmen em bovinos (Harmon e Mcleod, 2001). Apesar da necessidade de respostas adaptativas no transporte de glicose, Au et al. (2002) sugerem que talvez existam outros mecanismos responsáveis pelo transporte de glicose em bovinos, além do SGTL1.

As técnicas de infusão oferecem a vantagem de controlar o suprimento de carboidratos para 0 intestino delgado; entretanto, a maioria dos estudos utilizando infusão abomasal de carboidratos é de curta duração (<24h) e não considera os mecanismos fisiológicos de adaptação que podem estar envolvidos. Kreikemeier et al. (1991) realizaram a infusão de 20 e $40 \mathrm{~g} / \mathrm{h}$ de glicose e amido e observaram diminuição na digestibilidade no intestino delgado à medida que a quantidade utilizada na infusão aumentou. Estimando a digestibilidade verdadeira dos CNE no intestino delgado de novilhos, Branco et al. (1999), trabalhando com novilhos, utilizaram infusão abomasal com glicose, amido hidrolisado $10 \mathrm{~g} / \mathrm{h}, 20 \mathrm{~g} / \mathrm{h}$ e $40 \mathrm{~g} / \mathrm{h}$. Os autores observaram que o fluxo duodenal de glicose foi menor para os tratamentos com amido hidrolisado em relação ao tratamento com glicose e variou apenas $62 \%$ da infusão abomasal de glicose, sendo que a glicose desapareceu quase completamente do intestino.

Harmon et al. (2001) em estudo para determinar como o local de digestão do amido interage com o metabolismo visceral de glicose, utilizaram infusão de amido no rúmen e pós-rúmen, em novilhos. O fluxo visceral de nutrientes e o metabolismo de glicose foram medidos durante a infusão intravenosa com ${ }^{14} \mathrm{C}$-glicose. Baseados na estimativa da digestibilidade no intestino delgado de $90 \%$ para a infusão de amido, a estimativa da absorção da glicose visceral drenada pela veia porta indicou que de 38 a $56 \%$ do carboidrato utilizado na infusão foi digerido e absorvido como glicose.

Para avaliar o impacto das mudanças no local de digestão do amido, Huntington et al. (2006) calcularam o rendimento da energia digestível para cada região do trato gastrintestinal. Os valores para a eficiência foram: ruminal $80 \%$, intestino delgado $97 \%$ e intestino grosso $62 \%$. A digestibilidade no intestino grosso foi de $44 \%$ e os coeficientes de digestibilidade ruminal e do intestino delgado foram variados. Esses dados demonstraram que a mudança da digestão do rúmen para o intestino delgado diminui a eficiência da energia produzida quando a digestibilidade no intestino delgado foi menor que 75\%. Quando a digestibilidade no intestino delgado foi acima de $75 \%$, a eficiência na energia produzida aumentou pela mudança da digestão do rúmen para 0 intestino delgado.

O aumento na digestão do amido no intestino delgado vem sendo sugerido para aumentar a produção de proteína do leite, talvez por poupar aminoácidos de serem utilizados para a gliconeogênese no fígado (Nocek e Tamminga, 1991). A eficiência da utilização da energia para absorção de glicose no intestino delgado é maior do que a digestão do amido no rúmen (Owens et al., 1986) devido à redução das perdas por metano, fermentação e calor, e maior eficiência da utilização da energia metabolizável.

Entretanto, o local da digestão do amido pode apresentar grande impacto no perfil dos nutrientes absorvidos. Nocek e Tamminga (1991) concluíram com base em 
uma extensa revisão de estudos produzidos, que não existem evidências claras que a digestão pós-ruminal do amido aumente a produção de leite.

\section{GLICOSE}

Nos ruminantes, os carboidratos provenientes da dieta são fermentados em ácidos graxos de cadeia curta no rúmen e menos de $10 \%$ das exigências corporais de glicose são provenientes da digestão no trato gastrintestinal. Assim, a principal fonte de glicose para os ruminantes é a gliconeogênese, sendo o propionato o principal substrato (Young, 1977).

Em ruminantes o fígado tem grande capacidade de produzir glicose, mas este órgão não é um utilizador eficiente de glicose exógena. Assim, pequeno suprimento de glicose exógena estimula a rápida produção de insulina, que é o principal hormônio controlador da utilização de glicose pelos tecidos extra-hepáticos em ruminantes, apresentando ainda, ação no metabolismo de proteínas e lipídeos (Weeks, 1989).

A glicose é a principal fonte de energia para os tecidos nervosos e é essencial na síntese de polissacarídeos estruturais, glicoproteínas e glicolipídeos de todas as membranas das células, cartilagem, mucopolissacarídeos etc. A quantidade de propionato absorvida do rúmen em animais bem alimentados é freqüentemente suficiente para atender as exigências para a síntese de glicose. Segundo Bergman (1973), as exigências aumentam levemente na prenhez, mas não há evidências de maior redirecionamento do metabolismo de propionato em direção a síntese de glicose quando o suprimento dos precursores de glicose é limitado.

A mudança da digestão do amido do rúmen para o intestino delgado aumenta a absorção de glicose pelo sistema porta. Taniguchi et al. (1995) observaram que o metabolismo de glicose no fígado de vacas que foram submetidas à infusão de amido no rúmen, resultou em diminuição da glicose e lactato, mas aumentou acetato e $\beta$-hidroxibutirato, livres para os tecidos periféricos. Da mesma forma, Reynolds et al. (1998) submeteram vacas leiteiras à infusão de amido no abomaso e observaram que houve aumento na absorção de glicose, sem afetar a produção de glicose no fígado. Ainda, Richards (1999) citado por Huntington et al. (2006) determinaram que a mudança do local de digestão de $800 \mathrm{~g} /$ dia de amido, do rúmen para 0 intestino delgado, aumentou a utilização de glicose pelo sistema porta de 120 para $281 \mathrm{~g} /$ dia.

Alguns estudos com infusão duodenal ou ruminal de glicose ou propionato em vacas em lactação (Rigout et al., 2002) e infusão de amido hidrolisado em novilhos de corte (Lemosquet et al., 2003) sugerem que a utilização direta da glicose absorvida de tecidos viscerais corresponde a $28 \%$ da glicose disponível para absorção no intestino delgado.

\section{PECTINA}

A pectina é uma substância amorfa parcialmente solúvel em água e é completamente solúvel em detergente neutro. Portanto não é recuperada na fibra em detergente neutro (FDN) (Van Soest, 1994). Está localizada na lamela média da parede celular vegetal e funciona como substância de adesão entre as células, sendo, em parte, responsável pela rigidez dos tecidos vegetais (Devlin, 1975; Salisbury e Ross, 1991).

Os principais componentes das pectinas são o ácido galacturônico e ramnogalacturonanas. Contudo, a constituição em açúcares das moléculas de pectina contém pequena quantidade de glicose, xilose e arabinose. As moléculas de pectina estão ligadas covalentemente com a celulose e a hemicelulose. Ainda não foi demonstrada nenhuma ligação covalente da pectina com a lignina mesmo com 0 avanço da maturidade do vegetal (Hall, 1994).

Embora a taxa e a extensão da degradação da pectina seja similar aos 
carboidratos não-estruturais, a fermentação da pectina aumenta a produção de acetato e geralmente não determina a produção de ácido lático durante a fermentação (Hatfield e Weimer, 1995).

Avaliando a composição e digestibilidade aparente da silagem de bagaço de laranja, Ítavo et al. (2000) observaram coeficiente de digestibilidade aparente médio dos CNE de $89,21 \%$ e sugeriram que o bagaço de laranja é rico em amido, açúcares simples e pectina. A pectina é um carboidrato estrutural de alta e rápida degradação ruminal, atingindo 90 a $100 \%$ sendo, invariavelmente, o carboidrato complexo de mais rápida degradação ruminal (Van Soest, 1994).

Broderick et al. (2002) estudaram rações contendo grão úmido de milho, grão de milho quebrado ou mistura de grão úmido de milho + polpa cítrica, no desempenho e composição do leite de vacas. Os valores de consumo de matéria seca e produção de leite, gordura, proteína, lactose e extrato seco desengordurado foram menores nas dietas contendo polpa cítrica versus grão úmido de milho e grão de milho quebrado. Os autores concluíram que, comparado ao grão úmido de milho e grão de milho quebrado, o fornecimento de uma fonte de carboidrato rica em pectina, como a polpa cítrica, diminuiu o consumo e a produção de leite em vacas leiteiras.

\section{CONCLUSÕES}

O sistema de classificação de carboidratos solúveis no alimento não leva em consideração a natureza físico-química dos alimentos, classificando-os como carboidratos não-estruturais ou carboidratos não fibrosos.

Deve-se levar em consideração a relação carboidratos não estruturais $e$ carboidratos estruturais para otimização da fermentação ruminal.

A digestão do amido no intestino delgado é eficiente porque aumenta a absorção de glicose pelo sistema porta, e esta é enviada para o metabolismo visceral, poupando a glicose via propionato proveniente da gliconeogênese.

\section{REFERÊNCIAS}

ANTUNES, R.C.; RODRIGUES, N.M. Metabolismo dos carboidratos não estruturais. In: BERCHIELLI, T.T.; PIRES, A.V.; OLIVEIRA, S.G. Nutrição de Ruminantes. Jaboticabal: FUNEP, 2006. p.229253.

ARCHIMÈDE, H.; SAUVANT, D.; HERVIEU, J. et al. Digestive interactions in the ruminant: relationships between whole tract and stomach evaluation.

Animal Feed Science and Technology, v.54, p.327-340, 1995.

AU, A.; GUPTA, P.; SCHEMBRI, P. et al. Rapid insertion of GLUT2 into the rat jejunal brush-border membrane promoted by glucagons-like peptide 2 . Biochemistry Journal, v.367, p.247-254, 2002.

BEN-GHEDALIA, D.; YOSEF, E.; MIRON, J.; EST, $Y$. The effects of starch- and pectin-rich diets on quantitative aspects of digestion in sheep. Animal Feed Science and Technology, v.24, p.289-298, 1989.

BERGMAN, E.N. Glucose metabolism in ruminants as related to hypoglycemia and ketosis. Journal of Dairy Science, v.54, p.936-948, 1973.

BODINE, T.N.; PURVIS II, H.T.; LALMAN, D.L. Effects of supplement type on animal performance, forage intake, digestion, and ruminal measurements of growing beef cattle. Journal of Animal Science, v.79, p.1041-1051, 2001.

BRANCO, A.F.; HARMON, D.L.; BOHNERT, D.W. et al. Estimating true digestibility of nonstructural carbohydrates in the small intestine of steers. Journal of Animal Science, v.77, p.1889-1895, 1999.

BRODERICK, G.A.; MERTENS, D.R.; SIMONS, R. Efficacy of carbohydrate sources for milk production by cows fed diets based on alfalfa silage. Journal of Dairy Science, v.85, p.1767-1776, 2002.

CHESSON, A.; MONRO, J.A. Legume pectic substances and their degradation in ovine rumen. Journal of Science and Food Agriculture, v.33, p.852, 1982.

$\mathrm{CHURCH}$, D.C. Digestive Phisiology and Nutrition of Ruminants. 3.ed. Oregon: O \& B Corvallis, 1979. $350 \mathrm{p}$.

COOMER, J.C.; AMOS, H.E.; WILLIAMS, C.C. et al. Response of early lactation cows to fat supplementation in diets with different nonstructural 
carbohydrates concentration. Journal of Dairy Science, v.76, p.3747-3753, 1993.

DE VISSER, $H$. Characterization of carbohydrates in concentrates for dairy cows. In: GARNSWORTHY, P.C.; COLE, DJA. (Eds). Recent Advances in Animal Nutrition, 1993. Loughborough: Nottingham University Press, 1993, p.19-38.

DEVLIN, R.M. Plant physiology. $3^{\text {rd }}$ ed. New York: D. Van Nostrand Company, 1975, 600p.

FENG, P.; HOOVER, W.H.; MILLER, T.K. et al. Interactions of fiber and nonstructural carbohydrates on lactation and ruminal function. Journal of Dairy Science, v.76, p.1324-1336, 1993.

FONTY, G. The rumen anaerobic fungi. In: JOUANY, J.P. (Ed.). Rumen microbial metabolism and ruminant digestion. Paris: INRA, 1991, p.5370.

HALL, M.B. Pectin: the structural, non-structural carbohydrate. In: CORNELL NUTRITION CONFERENCE FOR FEED MANUFACTURES, 56., 1994, New York. Proceedings... New York: Cornell University, 1994, p.29-36.

HALL, M.B. Recent advanced in non-ndf carbohydrates for the nutrition of lactating cows. In: SIMPÓSIO INTERNACIONAL EM BOVINOS DE LEITE, 2., 2001, Lavras. Anais... Lavras: UFLA, 2001, p.139-148.

HARMON, D.L.; McLEOD, K.R. Glucose uptake and regulation by intestinal tissues: implications and whole-body energetics. Journal of Animal Science, v.79, p.E59-E72, 2001 (Suppl. E).

HARMON, D.L.; RICHARDS, C.J.; SWANSON, K.C. et al. Influence of ruminal and postruminal starch infusion on visceral glucose metabolism in steers. Canadian Journal of Animal Science, v.84, p.309-318, 2001.

HATFIELD, R.D.; WEIMER, P.J. Degradation characteristics of isolated and in situ cell wall Lucerne pectic plysaccharides by mixed ruminal microbes. Journal of Science and Food

Agriculture, v. 69, p.185, 1995.

HENRIQUE, W.; LEME, P.R.; LANNA, D.P.D. et al. Replacement of starch for pectin in diet with different concentrate levels. 1. Animal performance and carcass characteristics. Revista Brasileira de Zootecnia, v.27, p.1206-1211, 1998.

HILTNER, P.; DEHORITY, B.A. Effect of soluble carbohydrates on digestion of cellulose by pure cultures of rumen bacteria. Applied Environment Microbiology, v.46, p.642-648, 1983.

HSU, J.T.; FAULKNER, D.B.; GARLEB, K.A. et al. Evaluation of corn fiber, cottonseed hulls, oat hulls, and soybean hulls as roughage sources for ruminants. Journal of Animal Science, v.65, p.244255, 1987.

HUNTINGTON, G.B. Starch utilization by ruminants: from basis to the bunk. Journal of Animal Science, v.63, p.1634-1648, 1997.

HUNTINGTON, G.B.; HARMON, D.L.; RICHARDS, C.J. Sites, rates, and limits of starch digestion and glucose metabolism in growing cattle. Journal of Animal Science, v.84, p.E14-E24, 2006 (Suppl. E).

HUSSEIN, H.S.; MERCHEN, N.R.; FAHEY Jr., G.C. Effects of forage level and canola seed supplementation on site and extent of digestion of organic matter, carbohydrates, and energy by steers. Journal of Animal Science, v.73, p.2458-2468, 1995.

ÍTAVO, L.C.V.; SANTOS, G.T.; JOBIM, C.C. et al. Composição e digestibilidade aparente da silagem de bagaço de laranja. Revista Brasileira de Zootecnia, v.29, n.5, p.1485-1490, 2000.

JOUANY, J.P. Defaunation of the rumen. In: JOUANY, J.P. (Ed.). Rumen microbial metabolism and ruminant digestion. Paris: INRA, 1991, p.239261.

KREIKEMEIER, K.K.; HARMON, D.L.; BRANDT Jr. et al. Small intestinal starch digestion in steers: effect of various levels of abomasal glucose, corn starch and corn dextrin infusion on small intestinal disappearance and net glucose absorption. Journal of Animal Science, v.69, p.328-338, 1991.

KREIKEMEIER, K.K.; HARMON, D.L. Abomasal glucose, maize starch and maize dextrin infusions in cattle: Small intestinal disappearance, net portal glucose flux and ileal oligosaccharide flow. British Journal of Nutrition, v.73, p.763-772, 1995.

LEMOSQUET, S.; RIGOUT, S.; BACH, A. et al. Glucose metabolism in lactating cows in response to isoenergetic infusions of propionic acid or duodenal glucose. Journal of Dairy Science, v.87, p.17671777, 2003.

MARTIN, C.; PHILIPPEAU, C.; MICHALETDOREAU. Effect of wheat and corn variety on fiber digestion in beef steers fed high-grain diets. Journal of Animal Science, v.77, p.2269-2278, 1999.

MERTENS, D.R.; LOFTEN, J.R. The effect of starch on forage fiber digestion kinetics in vitro. Journal Dairy Science, v.63, p.1437-1446, 1980.

NATIONAL RESEARCH COUNCIL - NRC. Nutrient Requirement of Dairy Cattle. 6. ed. Washington: National Academic Press, 1989.p

NOCEK, J.E.; TAMMINGA, S. Site of digestion of starch in the gastrointestinal tract of dairy cows and its effect on milk yield and composition. Journal of Dairy Science, v.74, p.3589-3689, 1991. 
NOCEK, J.E.; RUSSELL, J.B. Protein and energy as an integrated system. Relationship pf ruminal protein and carbohydrate availability to microbial synthesis and milk production. Journal of Dairy Science, v.71, p.2070-2081, 1988.

OBA, M.; ALLEN, M.S. Effects of corn grain conservation method on ruminal digestion kinetics for lactating dairy cows at two dietary starch concentrations. Journal of Dairy Science, v.86, p.184-194, 2003.

OLSON, K.C.; COCHRAN, R.C.; JONES, T.J. et al. Effects of ruminal administration of supplemental degradable intake protein and starch on utilization of low-quality warm-season grass hay by beef steers. Journal of Animal Science, v.77, p.1016-1025, 1999.

ORPIN, C.G.; JOBLIN, K.N. The rumen anaerobic fungi. In: HOBSON, P.N.; STEWART, C.S. (Eds). The rumen microbial ecosystem, $2^{\text {nd }}$ ed. London: Blackie Academic and Professional, 1997, p.140195.

OWENS, F.N.; ZINN, R.A.; KIM, Y.K. Limits to starch digestion in the ruminal intestine. Journal of Animal Science, v.63, p.1634-1648, 1986.

PALMQUIST, D.L.; JENKINS, T.C. Fat in lactation rations: a review. Journal of Dairy Science, v.63, p.1-19, 1980.

PIWONKA, E.J.; FIRKINS, J.L. Effect of glucose fermentation on fiber digestion by ruminal microorganisms in vitro. Journal of Dairy Science, v.79, p.2196-2206, 1996.

REYNOLDS, C.K.; HUMPHRIES, D.J.; CAMMELL, S.B. et al. Effects of abomasal wheat starch infusion on splanchnic metabolism and energy balance of lactating cow. Journal of Animal Science, v.72, p.3196-3206, 1998.

RIGOUT, S.; LEMOSQUET, S.; VAN EYS, J.E. et al. Duodenal glucose increases glucose fluxes and lactose synthesis in grass silage-fed dairy cows. Journal of Dairy Science, v.85, p.595-606, 2002.

RODRIGUES, M.T.; VIEIRA, R.A.M. Metodologias aplicadas ao fracionamento de alimentos. In: BERCHIELLI, T.T.; PIRES, A.V.; OLIVEIRA, S.G. Nutrição de Ruminantes. Jaboticabal: FUNEP, 2006. Cap.2, p. 229-253.

RUSSELL, J.B.; O'CONNOR, J.D.; FOX, D.G. et al. A net carbohydrate and protein system for evaluating cattle diets: I. Ruminal fermentation. Journal of Animal Science, v.70, n.12, p.3551-3561, 1992.
SALISBURY, F.B.; ROSS, C.W. Plant physiology. 4thed. Belmont: Wadsworth Publishing Company, 1991. 336p.

SARWAR, M.; FIRKINS, J.L.; EASTRIDGE, M.L. Effects of varying forage and concentrate carbohydrates on nutrient digestibilities and milk production by dairy cows. Journal of Dairy Science, v.75, p.1533-1541, 1992.

TANIGUCHI, K.; HUNTINGTON, G.B.; GLENN, B.P. Net nutrient flux by visceral tissues of beef steers given abomasal and ruminal infusion of casein and starch. Journal of Animal Science, v.73, p.236249, 1995.

TEIXEIRA, J.C.; ANDRADE, G.A. Carboidratos na alimentação de ruminantes. In: SIMPÓSIO DE FORRAGICULTURA E PASTAGENS, 2., 2001, Lavras. Anais... Lavras: Universidade Federal de Lavras, 2001, p.1-58.

VALADARES FILHO, S.C. Digestão total e parcial da matéria seca e carboidratos em bovinos e bubalinos. 1985. Viçosa, 148f. Tese (Doutorado em Zootecnia) - Curso de Pós-graduação em Zootecnia, Universidade Federal de Viçosa.

VAN SOEST, P.J. Nutritional Ecology of the Ruminant. Ithaca: Comstock Publication Association, 1994. 476 p.

WEEKS, T.E.C. Hormonal control of glucose metabolism. In: INTERNATIONAL SYMPOSIUM ON RUMINANT PHYSIOLOGY, 7., 1989, Sendai.

Proceedings... San Diego: Academic Press, 1991, p.183-200.

WILLIAMS, A.G.; COLEMAN, G.S. The rumen protozoa. In: HOBSON, P.N.; STEWART, C.S. (Eds). The rumen microbial ecosystem, $2^{\text {nd }}$ ed. London: Blackie Academic and Professional, 1997, p.73-139.

XIONG, Y.; BARTLE, S.J.; PRESTON, R.L. Density of steam flaked sorghum grain, roughage level and feeding regime for feedlot steers. Journal of Animal Science, v.69, p.1707-1718, 1991.

YOUNG, J.W. Gluconeogenisis in cattle: significance and methodology. Journal of Dairy Science, v.60, n.1, p.1-15, 1977.

ZINN, R.A.; OWENS, F.N. A rapid procedure for purine measurement and its use for estimating net ruminal protein synthesis. Canadian Journal of Animal Science, v.66, p.157-163, 1986. 